\title{
Urine polymerase chain reaction as a screening tool for the detection of congenital cytomegalovirus infection
}

\author{
Y Schlesinger, D Halle, A I Eidelman, D Reich, D Dayan, B Rudensky, D Raveh, \\ D Branski, M Kaplan, V Shefer, D Miron
}

Arch Dis Child Fetal Neonatal Ed 2003;88:F371-F374

See end of article for authors' affiliations

Correspondence to: Dr Schlesinger, Infectious Diseases Unit, Shaare Zedek Medical Center PO Box 3235, Jerusalem 91031 , Israel; yechiel@szmc.org.il

Accepted 10 October 2002

\begin{abstract}
Objectives: To define the incidence of congenital cytomegalovirus (CMV) infection in a defined population in Israel as diagnosed by urine polymerase chain reaction (PCR), and to assess the utility of this method for screening for congenital CMV infection.

Design: A convenient sample of urine specimens from asymptomatic newborns were subjected to $\mathrm{CMV}$ PCR. Positive results were validated by urine tube culture and by determination of serum CMV IgM antibodies. Maternal CMV IgG was determined in a representative sample of mothers. Newborns with positive urine specimens underwent full clinical evaluation. Epidemiological characteristics of the mothers were extracted from the medical records.

Settings: Two medical centres in Israel with different population characteristics.

Patients: A total of 2000 newborns (1000 in each medical centre).

Main outcome measure: Presence of CMV DNA in the urine.

Results: Despite significant epidemiological differences between the populations in the two hospitals, the CMV seroprevalence was similar, $80.5 \%$ and $85 \%$. Fourteen of the 2000 newborns screened $(0.7 \%)$ were PCR positive. Urine culture was positive in nine of 10 specimens; IgM was positive in only two of 13 newborns with positive PCR. Eleven newborns underwent full or partial evaluation, and only one $(9 \%)$ was symptomatic.

Conclusions: The incidence of congenital CMV infection in the study population was $0.7 \%$; over $90 \%$ were asymptomatic. Urinary CMV PCR is a reliable, rapid, and convenient method, and thus may serve as a screening tool for the detection of congenital $C M V$ infection.
\end{abstract}

(CMV IgM) has been shown in several studies to be an insensitive method. $^{8}$

The seroprevalence of Israeli women of childbearing age in a recent study of 6126 parturient women was $84.3 \%,{ }^{9}$ leaving $15 \%$ of the women susceptible to primary CMV infection during pregnancy. Hence, routine screening for congenital CMV in Israel was deemed not to be justified. ${ }^{9}$ Given the pool of potentially CMV infected infants and the availability of the new PCR methodology, we initiated this study. The two primary aims were to $(a)$ evaluate the diagnostic accuracy of the PCR technique and $(b)$ delineate the incidence of congenital CMV infection in a defined population so as to evaluate the value of the PCR method as a mass screening tool.

\section{PATIENTS AND METHODS}

\section{Study population}

The study was conducted between 1 May 1998 and 31 August 311999 in two hospitals: Shaare Zedek Medical Center in Jerusalem (centre 1) and Ha'Emek Medical Center in Northern Israel (centre 2). These two medical centres were chosen because their populations differ in many epidemiological aspects from each other, and represent the heterogeneous population typical of the State of Israel. Two thousand neonates aged up to 3 days (1000 newborns each) were included. The ethics committees of the two participating hospitals approved the study. Informed written consent was obtained from the parents of each newborn.

Abbreviations: $C M V$, cytomegalovirus; PCR, polymerase chain reaction; BERA, brain stem evoked response audiometry 
Basic data on participating mothers, obtained from the hospital records, included maternal age, ethnic group (Jewish or non-Jewish), and residency (urban or rural).

\section{Specimen collection and processing}

The selection of newborns from whom specimens were collected was based on convenience. Urine specimens were collected into a sterile urine bag attached to the perineum after thorough cleaning. All the urine specimens were processed in the Infectious Diseases Molecular Diagnostic Laboratory at Shaare Zedek Medical Center. The specimens from centre 2 were stored at $4^{\circ} \mathrm{C}$, and transported on ice within one week to the laboratory. On arrival, they were labelled and boiled for 10 minutes at $100^{\circ} \mathrm{C}$ to denature proteins that may inhibit the PCR. All the samples were stored at $4^{\circ} \mathrm{C}$, centrifuged, and the supernatants used for the PCR.

\section{PCR assay}

Common methods to prevent contamination and false positive results were used, including separate rooms for setting up the reaction and detection of the products, UV irradiation of all the reaction components except the primers, the Taq polymerase, and the urine specimens, and use of plugged tips. ${ }^{10} \mathrm{~A}$ negative control tube was added to each PCR run.

One of two sets of primers was used for the screening. A positive result with either set was confirmed with the other.

The first primer set was:

\section{5' -CCGCAACCTGTGGCCCATGG-3'}

5'-CGTTTGGGTTGCGCAGCGGG-3'. This amplifies 139 bp from the gp64 late antigen region. ${ }^{11}$

The second primer set was:

\section{5'-AGCTGCATGATGTGAGCAAG-3'}

5'-GAAGGCTGAGTTCTTGGTAA-3'.This amplifies $147 \mathrm{bp}$ from the 4th exon of the human CMV immediate early antigen. ${ }^{12}$

The reaction mixture contained 12 pmol each primer, 200 $\mu$ mol each dNTP, 0.2 units Taq polymerase (SR Products, Sevenoaks, Kent, UK), and buffer containing $\mathrm{MgCl}_{2}$ at a final concentration of $1.5 \mathrm{mmol} / \mathrm{l}$, supplied by the same company. A $1.2 \mu \mathrm{l}$ sample of the urine to be tested was added to the reaction mixture to a final volume of $12.5 \mu$ l. The amplification was performed in a RoboCycler (Stratagene, La Jolla, California, USA). After initial heating at $95^{\circ} \mathrm{C}$ for two minutes, 32 cycles of $95^{\circ} \mathrm{C}$ for 30 seconds, followed by $65^{\circ} \mathrm{C}$ for 60 seconds were performed. The reaction was finished with 10 minutes at $65^{\circ} \mathrm{C}$. The reaction products were run on a 3\% agarose gel, and detected by staining with $0.5 \mu \mathrm{g} / \mathrm{l}$ ethidium bromide. Product sizes of 139 and 147 bp were consistent with a positive result of the late and immediate early antigens respectively.

\section{Urine culture}

A positive PCR result for a urine sample with either of the two primer sets were confirmed by tube culture and shell vial culture, using conventional methods. The cultures were performed on a fresh, aseptically collected urine specimen, in the Central Laboratory for Virology, Sheba Medical Center, Tel Hashomer, Israel.

\section{Preliminary assessment of urine PCR sensitivity}

The sensitivity of the PCR assay was determined by serial dilutions of a lysate of tissue culture infected by CMV in urine specimens randomly collected from the microbiology laboratory. The reaction was able to detect 5000 viral copies in $1 \mathrm{ml}$ urine. As the reliability of urine specimens for PCR has been previously challenged because of potential inhibitors, ${ }^{13}$ the PCR assay was repeated with multiple urine specimens. A total of 100 urine specimens randomly collected from the microbiology laboratory were spiked with $1.2 \mu \mathrm{l}$ of a tissue culture lysate. Positive results were consistently (99\%) found, with 20-30 viral copies/reaction $\left(2.5 \times 10^{4}\right.$ copies $\left./ \mathrm{ml}\right)$. The median
Table 1 Characteristics of mothers of 2000 newborns screened for congenital cytomegalovirus (CMV) infection

\begin{tabular}{ll}
\hline Characteristic & $\begin{array}{l}\text { Number } \\
(\%)\end{array}$ \\
\hline $\begin{array}{l}\text { Mothers with available data } \\
\text { CMV IgG seroprevalence (\%)* }\end{array}$ & 1939 \\
$\begin{array}{l}\text { Ethnic group } \\
\text { Jewish }\end{array}$ & 82.6 \\
$\quad$ Non-Jewish & $1414(73)$ \\
Number with urine positive for CMV & $14(0.7)$ \\
\hline $\begin{array}{l}\text { *Based on a representative sample of } 616 \\
\text { mothers. }\end{array}$
\end{tabular}

urine viral load in congenital CMV is very high, and was recently determined to be $1.6 \times 10^{5}$ copies $/ \mathrm{ml} .{ }^{14}$ Therefore the assay was deemed suitable for screening purposes.

\section{Serology}

Measurement of cord blood IgG antibodies against CMV was performed on $333(33.3 \%)$ consecutive mothers in centre 1 and $283(28.3 \%)$ consecutive mothers in centre 2, reflecting maternal CMV seroprevalence.

The serum of newborns with either positive urine PCR or tube culture for CMV in their urine specimen was tested for the presence of CMV IgM by antibody capture ELISA (DiaSorin, Saluggia, Italy).

\section{Clinical assessment}

Newborns with positive urine PCR infection were clinically assessed as follows:

- repeated complete physical examinations

- blood tests (complete blood count, kidney function tests, liver enzymes, CMV IgM)

- head ultrasonography or computed tomography scan for identification of brain calcifications

- retinal examination for diagnosis of chorioretinitis

- hearing evaluation by brain stem evoked response audiometry (BERA)

\section{Statistical analysis}

Data were analysed using the EpiInfo 6.0 software package. p Values were calculated by $\chi^{2}$, and by the Fisher exact test where indicated because of small numbers. $p<0.05$ was considered to be significant.

\section{RESULTS}

Overall, 2000 newborns were included in the study, of which $140(7.2 \%)$ were premature $(<37$ weeks gestation). There were differences in epidemiological aspects between the two centres with regard to ethnicity (Jews $v$ Arabs) and residency (urban $v$ rural). However, there was no significant difference in CMV seroprevalence between the two centres (80.5\% and 85\% in centres 1 and 2 respectively). Also, there was no difference in CMV seroprevalence between Jews and non-Jews, or between urban and rural residents (data not shown). As the rates were very similar, we combined the two groups and analysed them as one. Fourteen of the 2000 newborns $(0.7 \%)$ were found to have CMV DNA in their urine, consistent with congenital CMV infection. Maternal epidemiological data were available for 1939 newborns. Table 1 shows the major characteristics.

Table 2 summarises the clinical characteristics of the newborns with congenital CMV infection. Urine of 10 of the 14 newborns with positive urinary CMV PCR was cultured for CMV. The families of the other four either refused (two), were not available (one), or had left the country before the test was 
Table 2 Characteristics of infants with congenital cytomegalovirus (CMV) infection

\begin{tabular}{|c|c|c|c|c|c|c|c|c|c|c|c|}
\hline $\begin{array}{l}\text { Patient } \\
\text { No* }\end{array}$ & Sex & $\begin{array}{l}\text { Ethnic } \\
\text { group }\end{array}$ & $\begin{array}{l}\text { Gest. age } \\
\text { (weeks) }\end{array}$ & SGA & Microcephaly & $C M V \lg M$ & $\begin{array}{l}\text { Urine } \\
\text { culture }\end{array}$ & $\begin{array}{l}\text { Head } \\
\text { CT/US }\end{array}$ & $\begin{array}{l}\text { Retinal } \\
\text { exam }\end{array}$ & BERA & Blood tests† \\
\hline 1 & M & J & 40 & $\mathrm{~N}$ & $\mathrm{~N}$ & Negative & ND & ND & ND & ND & ND \\
\hline 2 & $\mathrm{~F}$ & J & 40 & $\mathrm{~N}$ & $\mathrm{~N}$ & Negative & Positive & Normal & Normal & Normal & Normal \\
\hline 3 & M & J & 39 & $\mathrm{~N}$ & $\mathrm{~N}$ & Negative & Positive & Normal & Normal & Normal & Normal \\
\hline 4 & M & J & 40 & $\mathrm{~N}$ & & Negative & Positive & Normal & Normal & Normal & Normal \\
\hline 5 & M & $\mathrm{J}$ & 37 & $\mathrm{~N}$ & $\mathrm{~N}$ & Negative & Positive & Normal & Normal & Normal & Normal \\
\hline 6 & $\mathrm{~F}$ & $\mathrm{~J}$ & 41 & $\mathrm{~N}$ & $\mathrm{~N}$ & Negative & Positive & Normal & ND & Normal & Normal \\
\hline 7 & $\mathrm{~F}$ & $\mathrm{~J}$ & 40 & $\mathrm{~N}$ & $N$ & Negative & Negative & Normal & ND & Normal & Normal \\
\hline 8 & M & J & 39 & $\mathrm{~N}$ & $N$ & Negative & ND & ND & ND & ND & ND \\
\hline 9 & $\mathrm{~F}$ & J & 40 & $\mathrm{~N}$ & $\mathrm{~N}$ & Negative & Positive & Normal & Normal & Normal & Normal \\
\hline 10 & M & J & 40 & $\mathrm{~N}$ & Y & Positive & Positive & Calcifications & Normal & Normal & $\begin{array}{l}\text { Hepatitis } \\
\text { Anaemia } \\
\text { platelets } \downarrow \downarrow\end{array}$ \\
\hline 11 & M & NJ & 33 & $\mathrm{~N}$ & $\mathrm{~N}$ & Negative & ND & Normal & Normal & Normal & Hepatitis \\
\hline 12 & $M$ & NJ & 40 & $\mathrm{~N}$ & $\mathrm{~N}$ & Negative & ND & ND & ND & ND & ND \\
\hline 13 & $M$ & NJ & 40 & $\mathrm{~N}$ & $N$ & ND & Positive & Normal & Normal & Normal & Normal \\
\hline 14 & $M$ & NJ & 28 & $\mathrm{~N}$ & $\mathrm{~N}$ & Positive & Positive & Normal & Normal & ND & Normal \\
\hline
\end{tabular}

*Patients 1 through 10 are from centre 1; patients 11 through 14 are from centre 2.

†Complete blood count, liver enzymes, renal function.

J, Jewish; NJ, non-Jewish; Gest, gestational; SGA, small for gestational age; CT, computed tomography; US, ultrasonography; exam, examination; BERA,

brain stem evoked response audiometry.

performed (one). Nine of the 10 cultures were positive for CMV. In the one culture negative case, three urine specimens collected on different occasions were strongly PCR positive with both primer sets, and culture, which was performed only once, was considered to be falsely negative. CMV IgM was measured in 13 infected infants and was found in only two neonates $(15 \%)$, one symptomatic and one asymptomatic. Eleven of the 14 newborns with congenital CMV infection underwent a full or partial evaluation according to the study plan. Two families refused, and one patient could not be evaluated because his parents had left the country before results of the PCR testing became available. Only one infected newborn (7\%) was symptomatic (No 10). He was born at term after an uneventful pregnancy with no prenatal evaluation. He was small for gestational age with a birth weight of $2510 \mathrm{~g}$ ( 3 rd centile) and a head circumference of $28.5 \mathrm{~cm}(<3 \%)$. He had hepatosplenomegaly and thrombocytopenia (80 000/ $\mathrm{mm}^{3}$ ) with petechial rash. The results of eye examination and BERA testing were normal. Brain ultrasonography and computed tomography showed severe periventricular calcifications. ${ }^{15}$ Another baby (No 11) had evidence of transient mild hepatitis.

\section{DISCUSSION}

The utility of PCR in place of urine culture and CMV IgM as a screening tool for congenital CMV infection is the most important finding of this study. Urine PCR was found to be very specific. We acknowledge that the sensitivity of the PCR assay was not directly assessed in this study, as urine cultures were not performed routinely on all the specimens. Furthermore, some investigators have questioned the validity of PCR results on urine specimens, because of the possible presence of PCR inhibitors in the urine. ${ }^{13}$ However, on the basis of our experiments showing 99\% PCR positivity in 100 urine specimens spiked with as low as 20-30 viral copies of CMV, we consider that we have shown the assay methodology to have almost $100 \%$ sensitivity, and therefore confirmed its value and utility as a screening tool. Urine PCR has also been successfully used as a screening method by Demler et $\mathrm{al}^{6}$ and Tsai et al. ${ }^{7}$ In the future, screening may become even simpler, with the option of DNA extraction from Guthrie filter paper and automated amplification of CMV sequences. ${ }^{16-18}$

The CMV IgM antibodies were negative in all but one of the asymptomatic CMV infected newborns. Melish and Hanshaw $^{8}$ have also found that only $50 \%$ of culture proven CMV infected newborns were IgM positive, and noted that the
IgM results tended to be positive along with higher titres in the symptomatic newborns. These results are very important for clinicians, because, although IgM is known not to be fully sensitive, this method is still considered reasonable for the diagnosis of congenital CMV infection.

We found a combined seroprevalence of $82.6 \%$. This is similar to that of Stein et al, ${ }^{9}$ who found a seroprevalence of $84.3 \%$ in 6126 women of childbearing age in Israel. It seems that, despite major differences among different subgroups in this country, the overall CMV seroprevalence is similarly very high, with a consequent incidence of CMV infection. Assuming a 4\% risk of primary CMV infection during pregnancy, $40 \%$ risk of fetal infection, and a $10 \%$ risk of early symptomatic infection, ${ }^{1}$ the 135000 annual deliveries in Israel translate to 30-35 cases of symptomatic congenital CMV infection. A similar number of infants who appear normal at birth are expected to develop late neurological dysfunction, primarily hearing deficits. ${ }^{1}$ We found congenital CMV infection in 14 of 2000 newborns, and if the same rate applies to the remainder of the country, about 945 cases can be expected to occur annually, most of which probably being the result of re-activation of previous infection. With the new data of Boppana et al ${ }^{19} 20$ showing symptomatic infection in infants of mothers with re-activation rather than primary CMV infection during pregnancy, the number of symptomatic patients for whom routine screening is justified may be higher than that estimated by Stein et al. ${ }^{9}$

The spectrum of the mass screening programme in many US states has been widened, and many states routinely screen for various diseases, including congenital infections such as HIV and toxoplasmosis. ${ }^{21-24}$ Both the incidence of congenital CMV, which is much higher than that of hypothyroidism or phenylketonuria, and our results suggesting that urine PCR screening is convenient and reliable, makes CMV an attractive object of screening. However, the justification for routine screening may be questioned because of the lack of a proven mode of intervention. On the other hand, it may be argued that the knowledge per se of the risk of sensory-neuronal damage in the CMV infected newborn should prompt close monitoring and early diagnosis and intervention. Furthermore, the results of the randomised, placebo controlled study of the NIAID study noted superiority of ganciclovir over placebo in the treatment of symptomatic patients in preventing hearing deterioration. ${ }^{525}$ These results are premature, and as yet no firm recommendations have been made. Therefore the role of such treatment for asymptomatic children needs to 
be fully studied. Hence, a screening methodology that can identify such potential asymptomatic patients should be welcomed.

In summary, this study illustrates the potential role of urine PCR as a screening method for the diagnosis of congenital CMV infection, and confirms the lack of sensitivity of the newborn IgM status for the same purpose. By using the urine PCR screening method, we were able to evaluate the magnitude of the problem in a defined population in Israel. These results may be the basis for future larger scale studies to evaluate the feasibility and effectiveness of a routine screening programme of newborns for the presence of congenital CMV infection.

\section{ACKNOWLEDGEMENTS}

We thank Dr Dana Wolf, Head of the Clinical Virology Laboratory, Hadassah-Hebrew University Medical Center, Jerusalem, for quantitation of the viral copies in the CMV cell culture lysate, and to Ms Nina Rabinowitz for her superb technical assistance.

This work was presented in part at the 37th conference of the Infectious Diseases Society of America (IDSA), November 1999, Philadelphia, USA.

\section{Authors' affiliations}

Y Schlesinger, D Halle, A I Eidelman, D Dayan, B Rudensky, D Raveh, D Branski, M Kaplan, Shaare Zedek Medical Center, Jerusalem, affiliated with Hebrew University School of Medicine, Jerusalem and Ben-Gurion Faculty of Medicine, Beer Sheva, Israel

D Reich, V Shefer, D Miron, Ha'Emek Medical Center, Afula, affiliated with Rappapot School of Medicine, Technion, Haifa, Israel

\section{REFERENCES}

1 Stagno S. Cytomegalovirus. In: Remington JS, Klein JO, eds. Infectious diseases of the fetus and newborn infant. 5th ed. Philadelphia: WB Saunders Co, 2001:389-424.

2 Demmler GJ. Summary of a workshop on surveillance for congenital cytomegalovirus disease. Rev Infect Dis 1991;13:315-29.

3 Brown HL, Abernathy MP. Cytomegalovirus infection. Semin Perinatol 1998;22:260-6.

4 Kumar ML, Nankervis GA, Gold E. Inapparent congenital cytomegalovirus infection: a follow-up study. N Engl J Med 1973;288:1370-2

5 Kimberlin DW, Lin CW, Sanchez P, et al. Ganciclovir treatment of symptomatic congenital cytomegalovirus infection: results of phase III randomized trial. 40th Interscience Conference on Antimicrobial agents and Chemotherapy (ICAAC), Toronto, Canada, September 2000, abstract 1942

6 Demmler GJ, Buffone GJ, Schimbor CM, et al. Detection of cytomegalovirus in urine from newborns by using polymerase chain reaction DNA amplification. J Infect Dis 1998;156:1177-84.
7 Tsai CH, Tsai FG, Shih YT, et al. Detection of congenital cytomegalovirus infection in Chineese newborn infants using polymerase chain reaction. Acta Paediatr 1996;85:1241-3.

8 Melish ME, Hanshaw JB. Congenital cytomegalovirus infection. Developmental progress of infants detected by routine screening. American Journal of Diseases in Children 1973;126:190-4.

9 Stein O, Sheinberg B, Schiff E, et al. Prevalence of antibodies to cytomegalovirus in a parturient population in Israel. Isr J Med Sci 1997;33:53-8.

10 Kwok S, Higuchi R. Avoiding false positives with PCR. Nature 1989;339:237-8.

11 Shibata D. Detection of human cytomegalovirus. In: Innis MA, Gelfand $\mathrm{DH}$, Sninsky JJ, et al, eds. PCR protocols: a guide to methods and applications. San Diego: Academic Press, 1990:368-71.

12 Jiwa NM, Van Gemert GW, Raap AK, et al. Rapid detection of human cytomegalovirus DNA in peripheral blood leukocytes of viremic transplant recipients by the polymerase chain reaction. Transplantation 1989;48:72-6.

13 Khan G, Kangro HO, Coates PJ, et al. Inhibitory effects of urine on the polymerase chain reaction for cytomegalovirus DNA. J Clin Pathol $1991 ; 44: 360-5$.

14 Kearns AM, Turner AJ, Eltringham GJ, et al. Rapid detection and quantification of CMV DNA in urine using LightCycler-based real-time PCR. J Clin Virol 2002;24:131-4.

15 Schimmel MS, Fisher D, Schlesinger Y. Periventricular calcifications in congenital cytomegalovirus infection. J Perinatol 2001;21:209-10

16 Fischler B, Rodensjo P, Nemeth A, et al. Cytomegalovirus DNA detection on Guthrie cards in patients with neonatal cholestasis. Arch Dis Child Fetal Neonatal Ed 1999;80:F130-4.

17 Johansson PJ, Jonsson M, Ahlfors K, et al. Retrospective diagnosis of congenital cytomegalovirus infection performed by polymerase chain reaction in blood stored on filter paper. Scand J Infect Dis 1997;29:465-8.

18 Shibata M, Takano H, Hironaka T, et al. Detection of human cytomegalovirus DNA in dried newborn blood filter paper. J Virol Methods 1994:46:279-85.

19 Boppana SB, Fowler KB, Britt WJ, et al. Symptomatic congenital cytomegalovirus infection in infants born to mothers with preexisting immunity to cytomegalovirus. Pediatrics 1999;104:55-60.

20 Boppana SB, Rivera LB, Fowler KB, et al. Intrauterine transmission of cytomegalovirus to infants of women with preconceptional immunity. $N$ Engl J Med 2001;344:1366-71.

21 American Academy of Pediatrics. Serving the family from birth to the medical home: a report from the Newborn Screening Task Force Convened in Washington DC, May 10-11, 1999. Pediatrics 2000; 106:S391-3

22 White KR, Maxon AB. Universal screening for infant hearing impairment: simple, beneficial, and presently justified. International Journal of Pediatric Otorhinolaringology 1995;32:201-11.

23 Downs MP. Universal newborn hearing screening: the Colorado story. International Journal of Pediatric Otorhinolaringology 1995;32:257-9.

24 American Academy of Pediatrics, Task Force of Newborn and Infant Hearing. Newborn and infant hearing loss: detection and intervention. Pediatrics 1990; 103:527-30.

25 Whitley RJ, Cloud G, Gruber W, et al. Ganciclovir treatment of symptomatic congenital cytomegalovirus infection: results of a phase II study. J Infect Dis 1997; 175:1080-6. 